\title{
Debate in Translating Nouns in the Holy Quran
}

\author{
Islam Al Momani (Corresponding author) \\ Princess Alia University College \\ Al Balqa Applied University Amman, Jordan
}

Nibal Malkawi

Al Balqa Applied University Salt, Jordan

Mona Smadi

Princess Alia University College

Al Balqa Applied University Amman, Jordan

Raed Khasawneh

Princess Alia University College

Al Balqa Applied University Amman, Jordan

Received: September 25, 2017 Accepted: December 7, 2017 Published: July 18, 2018

doi:10.5296/ire.v6i2.11908 URL: http://dx.doi.org/10.5296/ire.v6i2.11908

\begin{abstract}
The purpose of this paper is to investigate the semantic issues and problems related to nouns that some translators in their translation of the Holy Quran, couldn't translate it successfully such as Abdullah Yusuf and Souleymane Kanté. Although they did a great effort and their translation is successful but they fail to convey the meaning to some nouns. The researcher tried to introduce some suggestions to improve translation of nouns in the Holy Quran by
\end{abstract}


explaining some of these issues, and not to undermine these translations.

As the terminology of the Quran reflects the history of the rise of a monotheistic religion in Arabia, the terminology of its translation into Maninka reflects the long history of islamization of the Manding-speaking peoples, Souleymane Kanté's translation as an example. On the other hand, some Arabic translations to English are also available, Abdullah Yusuf's translation as an example.

The researcher investigated troubles these two translators face in translating the Holy Quran by providing some examples. It was clear that Yusufs' translation based on finding equivalent of nouns of the Quran in the target culture which is not always available, while Kante's translation based on that there are many words in the target language which can stand for any noun in the Holy Quran.

The researcher concludes that Kante's translation is better and more professional because languages develops and translators must always find equivalent words in the target culture to convey the meaning they are seeking to explain.

Keywords: Holy Quran, Equivalent, Transliteration, Inconsistency, Synonymy, Nouns

\section{Introduction}

The definition of translation is: to substitute a source language text (SLT) with a corresponding target language text (TLT). Contextual, semantic and socio cultural elements, of the source and target language texts, are combined in the translating process, which involves understanding, investigating, redefining and retexting. The concerns of the translator are many, among them, to provide the meaning of the source language and to keep equality of tone and style; among other things. In other words, the translation should be so good that it should be unable to distinguish it from the original. Following this idea can the Holy Quran be translated from Arabic into other languages? The opinion of translation philosophers is that it is impossible because the exact interpretation is known only to Allah. More to the point, the text of the Quran is so difficult that it should be interpreted before translating. It should be understood from this that, translation cannot replace understanding of meaning, especially, as Allah Almighty revealed His book for three main reasons: to be guidance for His creation; humankind and jinn, supporting the call of Muhammad (Gods peace be upon him) by being a miracle, and as a means of worship by reciting it (Zarquani, 2003). These points cannot be achieved by translation of the Quran. Therefore, it is ascertained that, 'translation' in the title above means "interpreting one's message in another language".

\subsection{Purpose of the Study}

This study aims at investigating the semantic issues and problems related to nouns that some translators in their translation of the Holy Quran, couldn't translate it successfully such as Abdullah Yusuf and Souleymane Kanté. 


\subsection{Questions of the Study}

This study attempts to answer the following questions:

1. What are the semantic problems facing Abdullah Yusuf and Souleymane Kanté in the translation of nouns in the Holly Quran?

2. Do they have different opinions on the challenges facing translators when translating nouns in the Holy Quran?

\section{Literature Review}

Al Jahni and Al Saleh (2016) conducted a study to investigate the orientalists' translations of the names of Qur'an Surahs which contain problems since they may be altered for literal and connotative meanings. The purpose of study lies in two different fields of knowledge:

First: A virtual methodology of the translators' works: What they accomplished and what they attempted to achieve.

Second: The findings of old theories in terms of the uniqueness of Qur'an and being separated from humans' discourse. Such proof may be used in the situation of imitation and translation. From this perspective we understand the inaccurate interpretation as well as the unaccepted translation.

Al-Suyuti (1988) mentioned the section names of the (Ayat) in the seventeenth type when talking about "know his names and the names of his Surahs," as for Al-Zarkshi, he organized the names of the Surahs in the fourteenth type "know the division according to its Surahs and the order of the Surahs and verses and its number", then Al-Suyuti mentioned the names of the Surahs with an interpretation or the names of Quran or the difference between them to mention then the problem of the amount of names, does it depend on what appears from the events? It seems overlap in the curriculum is clear and apparent that al-Suyuti seeks to take note of the phenomenon of naming the Surahs and justification, to justify this phenomenon with introductions

\section{Methodology}

The researchers used the qualitative approach in conducting this study by making a comparison between the translation of the two translators Abdullah Yusuf and Souleymane Kanté, and show the pros and cons of each translation, then reached a decision relating their translation.

\section{Results and Its Discussion}

\subsection{Semantic Problems in the Quran}

Two kinds of semantic problems face translators in translating the Quran. The first type is common to all translators that things are expressed differently from language to language (although some languages express things universally) and languages are different in culture and social direction. The second type of problems is specific to the translation of the Quran itself. 


\section{Ml Macrothink}

International Research in Education

ISSN 2327-5499

2018, Vol. 6, No. 2

I. Semantic problems in translation: There are many examples of semantic problems in the Divine text; the following are discussed among them:

1. Two words seemingly synonymous but different semantically, this can be shown in two ways: the semantic extension of a word in one language versus the semantic intension in another. For example the word الأب in the Quran can mean الأب (father) and الجد (forefather).

2. Taboo and euphemistic words: Simpler words should be compensated for some words. In other words, euphemistic words should be replaced for taboo words. For example, the word 'pregnant' is replaced by 'expectant mother' or 'mother to be'. Words are sometimes translated into words, without realizing, that there are better ways of translating them.

3. Difference of Lexicalization: As stated before, languages are different in lexicalizing. Some languages lexicalize particular things and others do not. This causes what is known as "lexical gap", meaning, words in one language having no equivalent in other languages.

4. Metaphor: A metaphor means applying a word to a use to which it literally cannot be associated (White, 1996: 9). Mostly, it is used to express a meaning that is not literal, by using any words or sentences. Modern usage and an early traditional definition of such meanings are regarded as metaphorical (Cooper, 1986: 12-13). Languages express many ideas using different metaphors. Therefore, metaphor is a semantic problem that the translator faces because once the metaphorical phrase has been translated literally it won't be what was originally meant.

\subsection{Lexical Problems in the Quran:}

1. The word الله (Allah): There is a disagreement by Muslim and non Muslim translators about the suitable translation of the word الله They disagree whether to use transliteration or use the word 'God'. The translators who use the word God are A.Y. All, M. Pickthal, M. Asad, Rodwell, Sale, Palmer, Arberry, and Bell, and those who use the word الله are Hilali and Khan, and King Fahd Holy Quran printing complex (The Holy Quran-an, English Translation of the Meanings and Commentary).

2. The Beautiful Names of Allah: Translators are not unified on agreeing to the translation of the Beautiful names of Allah, indicating the impossible task of comprehending these meanings. What makes a great translator is the translators' knowledge Stephen Straight (1979). The translator will not understand the text if he lacks knowledge of the cultural background of the author of the source text (Rose, 1981: 41).

3. The letters that begin particular verses: twenty nine verses begin with these letters (which total fourteen). Exegetes and translators have not been able to translate these words, only coming up with opinions and assumptions. Transliteration is used to render them into the target language.

\subsection{Inconsistency}

Throughout history, no doubt, there has been a great deal of effort by translators of the meaning of the Holy Quran. However, many scholars and translators have brought up the 
matter of differences in translating the meanings of the Holy Quran. Obviously there is no comparison between the translation of the Quran and its original Arabic form, regarding beauty and style, which has been described as "by turns, striking, soaring, vivid, terrible, tender and breathtaking." Although, I found when two words mean the same in context they should be used with the same English translation of that word throughout the translation, or it can be difficult to compare the English and the Arabic words. All the English translations of the Holy Quran put more effort in rendering a verse than giving the precise representation of the word. An example is in one translation, the verb in English 'to turn' is used for over forty three different Arabic words and the noun 'sin' is used for over twenty three. (Bakhtiar 2008).

\subsubsection{Abdullah Yusuf Translation}

This case is true for Abdullah Yusuf' translation of the meaning of the Holy Quran. There is no perfect synonymy in language because they may be from different diallects or styles, have different emotional meanings and are collocationally restricted. Some linguists are certain there are no complete or perfect synonyms in the Holy Quran. To prove that two words are synonyms, or not, one would have to look at all the possible contexts that they can occur in, which is impossible. In a text like the Holy Quran to use five different words to explain one word, in the source language, would be confusing and unacceptable and add to it not being understandable. Usually synonyms are used to avoid wordiness, but this style cannot be used here with an automotive text like the Holy Quran.

It is true to say that no two texts have the same meaning i.e. there cannot be any real synonymies. If two words were to have the same meaning, neither would survive in a language (Palmer 1976, 66).

Controversy has been caused over the idea of synonymy in the Holy Quran, by Muslim scholars, arguing there is no such thing because every word in the Holy Quran communicates a message that no other words can.

A parallel of synonymy is inconsistency at word levels. Words that have the same meaning are called synonyms, for example small and little. The Arabic word "عذاب" /adaab/ is interpreted into "the Wrath", "the Penalty", "the Punishment" and "torment" in (1), (2), (3), and (4) respectively. These ideas show the idea of synonymy whenever we discuss inconsistency.

There is nothing called synonymy when it comes to the Holy Quran. The Muslim will find this when he/she looks closely at the meanings of the words and realizes that each single letter has been chosen carefully. Two words may seem similar but each conveys its own meaning (Sharawi 1993, 47. vol. 1).

For a translation to be accurate it must be consistent, meaning, throughout the text the concept should be translated in the same way. If a concept is translated in many ways it gives the impression that the word has multiple meanings, which is contrary. A translator is always in need of synonymy as a compromise to translate more important parts of the text (Newmark 1987). 


\section{Macrothink

Where a word is not important for componential analysis, or literal translation, it would be suitable to use synonymy. Here accuracy comes after economy (Newmark 1988, 84).

Synonymy should not be use to avoid repeating a word in a text like the Holy Quran, because each word has a meaning no other word has. Synonymy should only be used when there is no word in the target language that expresses the perfect meaning. The translator will avoid repetition by using synonymy in the translating of the Holy Quran but the translation will be inconsistent.

Sometimes the translator lacks in knowledge that a word in Arabic can have more than one meaning, depending on the context it occurs. For example the word "آيات"/ayaat/ means "verses" of the Holy Quran or "signs", "evidence" or "miracles". In some cases it pertains to all the possible meanings it communicates. Look at these examples:

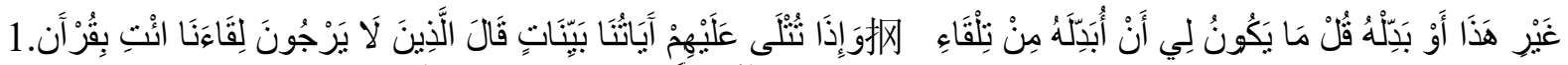

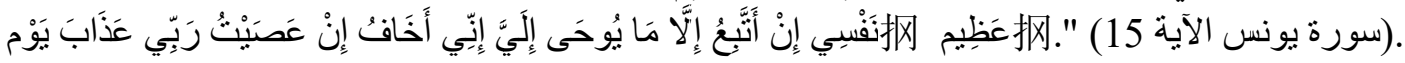

1. "But when Our Clear Signs

Are rehearsed unto them,

Those who rest not their hope

On their meeting with Us,

Say: "bring us a Quran

Other than this, or change this, ..."

(Surah 10: 15)

There is a misinterpretation of the word "آيات" /?aayaat/, in this example, by interpreting it as "signs". However, it is clear that the word here means 'verses' of the Holy Quran from the context that it occurs in. Mentioned in the verse itself these "verses" are recited, and more importantly, the unbeliever would say: "bring us a Quran other than this".

Therefore, the way that the word "يآيات" ?aayaat/ contextually occurs makes it obvious that it refers to verses of the Holy Quran, not the "signs" or "miracles" of the prophets, even though this word does have a similar meaning, but not in this context. This word is translated incorrectly in many similar occurrences including $(1: 129 ; 2: 113 ; 10: 1 ; 2: 11)$

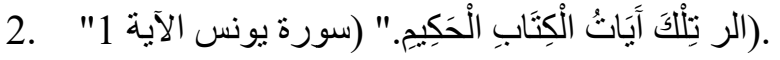

2. "A. L. R.

These are the Ayats

Of the Book of Wisdom"

(Surah 10:1)

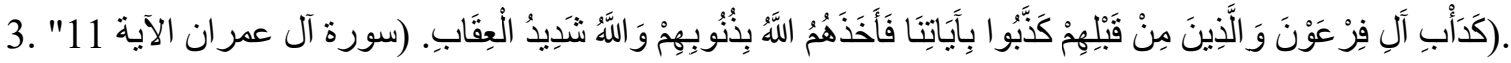

3. "Their plight will be

No better than that

Of the people of Pharaoh,

And their predecessors: 
They denied our Signs.

And God called them to account for their sins.

For God is strict In Punishment."

(Surah 3: 11)

The translator contends that the word "آيات" /aayaat/ here means "signs" or "verses of the Holy Quran, simultaneously. The translator suggests both meanings should be understood. Therefore, the word is transliterated to mean "signs" or "verses. What is understood is that every time the word "آيات" /?aayaat/ has two meanings it should be transliterated or have consistency in the translation, but this is not done by the translator.

Yusuf Ali uses the word "signs" to mean "verses" in example 1, and to mean "miracle" or "evidence" in example 2. He wrongly transliterated the same word. Is there consistency in this method of translating? The answer is, obviously, no.

The researcher, however, understands what the word "آيـات /?aayaat/ in these particular contexts mean: example 1 refers exclusively to the verses of the Holy Quran, where they tell us about different miracles or evidence brought by many prophets. Example 3 refers to when the people of Pharaoh and those before them denied the "signs" of Allah. Muslim, Christian and Jewish history tells us that Moses came to Pharaoh with miracles and signs not verses, like a Holy book, although the Torah was sent to the people of Israel, and not to Pharaoh.

\subsubsection{Souleymane Kanté Translation}

Because Souleymane Kanté was a child of marabout family, he has a clear idea about the tradition of clarification on the Quran in Manding languages. The Manding marabouts almost agreed on the translation of some particular parts of the Holy Quran. Kanté also depend on this fact in his translation of the Holy Quran.

Kanté in his translation tried to include only words that are used in spoken language, although he created some words to refer to newly created concepts or words such as TV, computer, airplane, etc. to replace words rooted deeply in the language. Because these words were used widely, so the translation of the Holy Quran in such way was not an exception. Large number of words appeared in his translation.

On the contrary of Abdullah Yusuf, Kante never depends on finding equivalent words in the target culture, but he always has the ability to find words and expressions easily to express the meaning and to convey the message which is included in the verse.

He used three approaches relating the borrowing of words:

- Retention of a loanword;

- terminologization of a familiar words in Manding language so the translator can avoid an existing loanword in the original language;

- Creation of neologisms in order to substitute existing loanwords in the original language.

These approaches will be discussed below. 
1) Retention of a loanword is uncommon. In most cases the translators never keeps the borrowed word in its current meaning. The names of God Ála (from Ar.'allah ) and of the Quran kùraná (Ar. qur'ān ) are the most evident examples of this approach.

An example is the following verse:

1. SG too POS religion-ART COP 1 SG LOC

دِينِ وَلِيَ دِينُكُمْ لَكُمْ

'To you your religion, and to me my religion!'

2) Terminologization: here the translator choose a word from the everyday language and finds a word in the Manding language which has the same meaning or very close to it. For example, the verb pálanka has meanings 'to divorce' and 'to quit the community'. The meaning 'to renounce the Islamic faith' is what existed in the Quranic context, therefore pálankabaa 'apostate'.

Another example is:

spirit-A RT PL PP

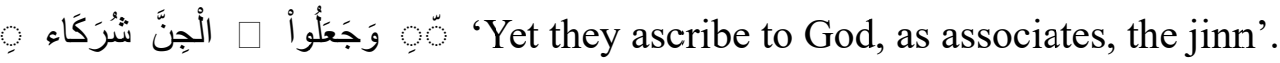

3) Creating neologisms. Here they replace a borrowed word with another one which exist in the Manding language. Putting in mind that this neologism could be easily understood by people who speak the Manika language. There are many examples of this group which exist in the Holy Quran such as: fóda 'sura', from fo' 'to say' and dá 'number', literally, 'the number of the speech', cf. the loanword súra(n) from Ar. sūra .

\subsection{Discussion}

It is clear from what I stated above that these two translators Abdullah Yusuf and Souleymane Kanté have two different opinions in translating nouns in Holy Quran. Abdullah Yusuf claimed that there are troubles in translating nouns of the Holy Quran because the translator may not find equivalent word in the target language or the target culture, while in the other hand, Souleymane Kanté didn't mention culture of the target language at all. In his opinion the Mandy language (his language) contains words that can be used to express the meaning of the verse in the Quran. He claimed that each language contains many synonyms that can stand for any word in the Holy Quran. From my own point of view, Kanté's opinion is better than Yusuf's opinion, Kanté's translation of the holly Quran is more professional because he can convey meaning to people who speaks Mandy, but Yusuf, as it was clear from the examples above, fails to translate some verses in the Quran in a proper way, he used different meaning and words to refer to the same word in the Holy Quran. He was not consistent at all.

\section{Conclusion}

It is obvious that there are limitations when translating the Holy Quran, these are semantic problems because some expressions in Quran don't have equivalents in the target culture. In 
such case a translator may use more than one word in the target language to clarify the meaning. Sometimes translators need to make explanations to in the target language to clarify the meaning.

In this report I tried to investigate some semantic problems relating to nouns that some translators such as Abdullah Yusuf and Souleymane Kanté have when they translate the Holy Quran, they translate these nouns unsuccessfully. Moreover, many reasons where identified for this confusion in translating: first synonyms are used by the translators; second when words have straightforward equivalents translators use transliterated words. Of course, this doesn't mean that I undermine the great job of these translators, but I only shed light on some issues they don't agree on all.

\section{References}

Al-Suyuti, J. (1988). Mastery in the sciences of the Qur'an, the investigation of Muhammad Abu al-Fadl Ibrahim, the modern library. Beirut, 1, 150.

Al Jahni, N., \& Al Saleh, A. (2016). Translation of the Quran: Between the orbit of systems and the problem of interpretation. Journal of Al Ather, 24.

Bakhtiar, L. (2008). The Sublime Quran. Retrieved from www.sublimequran.org

Cooper, D. E. (1986). "Metaphor", Aristotelian Society Series, Vol.5, Basill Blackwell, Oxford, $12-13$.

Newmark, P. (1988). A Textbook of Translation. Prentice Hall International (UK) Ltd,

Palmer, E. (1900). The Koran. Oxford: The Clarendon Press.

Quran. The Holy Qur-an. English Translation of the Meanings and Commentary. Revised and edited by the Presidency of Islamic Researches, IFTA Call and Guidance. Al-Madina Al-Munawarah: King Fahd Holy Qur-an Printing Complex, n.d. [1405 A.H.].

Sharawi, M. (1993). Mu jizat Al Qura `n Al Kareem, voll.

Straight, S. (1981). Knowledge, Purpose, and Intuition : Three Dimensions in the Evaluation of Translation. In Marilyn G. Rose (ed.)

Zarquani, M. (2003). Al Erfan in Quran studies. Egyptian book house.

\section{Copyright Disclaimer}

Copyright reserved by the authors.

This article is an open-access article distributed under the terms and conditions of the Creative Commons Attribution license (http://creativecommons.org/licenses/by/3.0/). 